\title{
UM “BEST-SELLER” FRANCÊS NA BELÉM OITOCENTISTA: NOTAS SOBRE A CIRCULAÇÃO E RECEPÇÃO DO ROMANCISTA PAUL DE KOCK
}

\begin{abstract}
RESUMO
Os estudos acerca da história do livro e da leitura revelam a intensa circulação da prosa de ficção francesa no Brasil durante o século XIX. Paul de Kock está entre os romancistas franceses que mais circularam nessa época, sobretudo em livrarias e gabinetes de leitura, bem como em jornais da época. O objetivo do presente artigo é discorrer sobre a circulação do referido romancista na Belém oitocentista, bem como sobre a recepção crítica do escritor francês.
\end{abstract}

Palavras-chave: Paul de Kock. Prosa de ficção francesa. Século XIX. Circulação. Recepção crítica.

\section{ABSTRACT}

The studies about the history of the book and the reading reveal the intense circulation of French prose fiction in Brasil during the nineteenth century. Paul de Kock is among the most circulated French novelists of the time, especially in bookstores and reading cabinets, as well as in nineteenth-century newspapers. The purpose of this article is to discuss the circulation of the said novelist in Belém the 19th century, as well as on the critical reception of the French writer.

Keywords: Paul de Kock. French fiction prose. Nineteenth century. Circulation. Critical reception.

1 Doutoranda pela Universidade Federal do Pará (alessandraverbum@yahoo.com.br), bolsista Capes.

2 Doutora em Teoria e História Literária pela Universi- dade Estadual de Campinas (UNICAMP) e Pós doutorado em História Cultural pela Université de Versailles Saint-Quentin-en-Yvelines. Atualmente é professora adjunta de Literatura Brasileira na Universidade Federal do Pará (UFPA). augustivaleria@ufpa.com. 


\section{INTRODUÇ̃̃O}

Paul de Kock foi um prolífico escritor francês, extremamente popular no século XIX, tanto em seu país de origem quanto em outros. Publicou dramas, vaudevilles, óperas cômicas e uma quantidade significativa de romances. Kock nasceu em Passy (Paris) em 21 de maio 1793 e faleceu em 29 de agosto de 1871. Escreveu seu primeiro romance L'enfant de ma femme (1812) aos 17 anos, muito embora só tenha obtido sucesso anos depois com o romance Gustave, le mauvais sujet (1821). Sua fama se dá, principalmente, pela publicação de suas obras em jornais nos chamados folhetins, espaços reservados nos jornais para a publicação diária ou semanária de capítulos de romances. O sucesso de seus folhetins garante-lhe lugar privilegiado entre os romancistas franceses populares de sua época, bem como o imprime a imagem de um romancista popular, lido, sobretudo, pelas classes econômicas mais baixas.

No Brasil, grandes autores coetâneos ou não ao escritor não deixaram de atestá-lo como mania de seu tempo. Graciliano Ramos confessa não apenas tê-lo lido na adolescência, bem como preferir suas leituras e as de Júlio Verne em detrimento de outras:

como levava uma vida bastante chata, habituei-me a ler romances. Os indivíduos que me conduziram a esse vício foram o tabelião Jerônimo Barreto e o agente do correio Mário Verâncio, grande admirador de Coelho Neto e tambem literato, autor dum conto que principiava assim: - Jerusalém, a deicida, dormia sossegada à luz pálida das estrelas. Sobre as colinas pairava uma tênue neblina, que era como o hálito da grande cidade adomecida. Um conto bonito que elogiei demais, embora intimamente preferisse o de Paulo de Kock e Júlio Verne. Desembestei para a literatura. (RAMOS apud SILVEIRA, 1998, p. 279).

Lima Barreto o cita em uma de suas obras mais conhecidas, Triste fim de Policarpo Quaresma. Na referida obra, as novelas de Paul de Kock parecem ser as únicas leituras que mantêm desperto o pedante Dr. Borges, que adormece ao tentar ler tratados e outros escritores franceses atualmente mais reconhecidos pela crítica literária como Guy de Maupassant ou Daudet. Contudo, no intuito de manter as aparências e iludir-se a si mesmo e aos demais conhecidos, o personagem lê os livros de Paul de Kock em capas trocadas:

À noite, ele abria as janelas das venezianas, acendia todos os bicos-de-gás e se punha à mesa, todo de branco com um livro aberto sobre os olhos. O sono não tardava a vir ao fim da quinta página... Isso era o diabo! Deu em procurar os livros da mulher. Eram romances franceses, Goncourt, Anatole France, Daudet, Maupassant, que o faziam dormir da mesma maneira que os tratados. Ele não compreendia a grandeza daquelas análises, daquelas descrições, o interesse e valor delas, revelando a todos, à sociedade, a vida, os sentimentos, as dores daqueles personagens, um mundo! O seu pedantismo, a sua falsa ciência e a pobreza de sua instrução geral faziam-no ver, naquilo tudo, brinquedos, passatempos, falatórios, tanto mais que ele dormia à leitura de tais livros.

Precisava, porém, iludir-se, a si mesmo e à mulher. De resto, da rua, viam-no e se dessem com ele a dormir sobre os livros?!... Tratou de encomendar algumas novelas de Paulo de Kock em lombadas com títulos trocados e afastou o sono (BARRETO, 1984, p. 165-166).

Monteiro Lobato o cita em seu livro Cidades Mortas ao retratar a vida lite- 
como um dos três únicos autores que figuravam entre o repertório de leituras dos habitantes de Oblivion (LUCA, 2007). Paul de Kock foi ainda citado no poema Precisa-se de uma dama de leite, do poeta, teatrólogo e caricaturista Luiz Carlos Peixoto de Castro. No romance Paulo (1861), do escritor oitocentista Bruno Seabra é considerado o - rei de Eugênio, personagem que se dizia poeta e tinha o desejo de fazer fortuna com o ofício:

Eugênio, chamava-se o amigo de Paulo, representava ter 25 ou 28 anos de idade. O seu mundo dizia ele, era a sua consciência, o seu conselheiro a circunstância, o seu rei Paulo de Kock, e a sua pátria a cabeça de Sócrates, um cão por que se desvelava extremosamente (SEABRA, s.d., p.5).

Tais testemunhos evidenciam que o romancista alcançou vasta circulação no Brasil dos séculos XIX e início do século XX.

\section{CIRCULAÇÃo DE PAUL DE KOCK NO BRASIL DURANTE O SÉCU- LOXIX}

Diversos estudos, sobretudo na área da história cultural, têm revelado a intensa circulação da prosa de ficção francesa no Brasil durante o século XIX. Andréa Müller, em pesquisa sobre a presença da prosa de ficção francesa no Brasil a partir de anúncios de romances publicados no Jornal do Commercio do Rio de Janeiro - entre os anos de 1857 e 1858 - , atenta para a grande quantidade de títulos oriundos dessa nação nesses anúncios, tanto traduzidos para a língua portuguesa quanto na língua original. Somente no ano de 1857 a pesquisadora identificou "249 títulos de narrativas ficcionais anunciadas no Jornal do Commercio, das quais 186 eram francesas. Em 1858, foram 259 narrativas anunciadas, entre as quais 185 francesas" (MÜLLER, S.d., p. 27). Müller afirma, ainda, que eram os romancistas franceses que mais comumente tinham suas obras anunciadas nesse jornal. Dentre os autores cujas obras foram anunciadas com mais frequência no ano de 1857 estavam Alexandre Dumas, com 33 romances anunciados, Balzac, com 24, Eugène Sue, com 12 e Paul de Kock, com 11 (MÜLLER, S. d, p. 67).

Juliana de Queiroz, por sua vez, em estudo sobre a presença de romances em um catálogo da livraria Garnier, assinala que no universo dos títulos traduzidos "os franceses reinavam absolutos", sendo os mais frequentes: Alexandre Dumas, Octavio Feuillet, Paul Féval, George Sand, Eugène Sue e Paul de Kock (QUEIROZ, 2008, p. 211).

Nos catálogos dos gabinetes de leitura do Brasil novamente os romances franceses parecem reinar absolutos. Nelson Schapochnik, em pesquisa no acervo do Real Gabinete Português de Leitura (RJ), observou a predominância de romances franceses em seus catálogos. Entre os autores com número de obras significativo nessas fontes, figuravam Alexandre Dumas, Paul de Kock, Eugène Sue, Frederic Souliè e George Sand (SCHAPOCHNIK, 1999). A pesquisa de Ana Luiza Martins, que se propôs a discorrer sobre os gabinetes de leitura instalados na Província de São Paulo, revelou, em específico, qual era a composição do gabinete de leitura sorocabano, fundado em 1867. A partir da análise de dois catálogos da instituição referida pode verificar a predominância de obras estrangeiras traduzidas que se compunha, sobretudo, por romances de procedência francesa. Entre os romancistas franceses com maior número de títulos nesses catálogos estavam Alexandre Dumas, Eugène Sue, Julio Verne e Paul de Kock (MARTINS, 1990).

A partir de tais pesquisas observa-se que Paul de Kock está entre os romancistas franceses que mais circularam no Brasil do Oitocentos, sobretudo em livrarias e gabinetes de leitura, bem como em jornais da época que traziam muitos de seus folhetins, anúncios de vendas e leilão de seus livros (em francês e em português). $O$ primeiro romance a ser publicado em folhetim no Brasil foi de sua autoria, Edmundo 
3 Conferir: AUGUSTI, Valéria. O livreiro e o gabinete: considerações sobre uma parceria comercial. In: II LIEHD (Seminário Brasileiro Livro e História Editorial. Disponível em: www.livroehistoriaeditorial. pro.br/ii_pdf/Valeria_Augusti. pdf

4 Antonio Maria Pereira. Lisboa, 28.08.1868

5 Pigoreau foi um dos principais livreiros-editores da Paris oitocentista e grande fornecedor dos gabinetes de leitura. Conferir: ABREU et alli. Caminhos do romance no Brasil: séculos XVIII e XIX. Disponível em: <www.caminhosdoromance.iel.unicamp.br/estudos/.../ caminhos.pdf>. Acesso em 12 de janeiro de 2013

6 Antonio Maria Pereira. Lisboa, 28.08.1868 e sua prima, publicado no Jornal do Commercio, do Rio de Janeiro, no dia 4 de janeiro de 1839 (NADAF, 2009). Em 1858, o Diário do Gram-Pará, na seção vendas, notificou a chegada de vinte e cinco diferentes títulos do autor no armazém do Sr. João José Dias da Costa, localizado na Rua do Açougue, no 7, Província do Pará. Tais títulos são os seguintes: O Amante da Lua, A Procura de Uma Mulher, André o Saboyanno, O Bigode, Este Senhor! Família Gó-Gó, O Filho de Minha Mulher, Frere Jacques, Georgeta, Gustavo ou A Boa Peça, O Homem da Natureza e o Homem Civilisado, Um Jovem Encantador, O Homem dos Três Calções, A Irmã Anna, João, A Leiteira de Montfermeil, A Mulher O Marido eo Aman'te, A Menina do $5^{\circ}$ Andar, Nem Sempre Nem Nunca, Phisiologia do Homem Casado, Robineau e Fifina, O Sem Gravata, Sr. Dupont, Taquinet, Um Bom Rapaz (SALES, S.d, p.3) Esse número é bastante considerável se comparado a autores que hoje são considerados grandes nomes da Literatura como o português Almeida Garret, cujas obras chegadas no referido armazém e no mesmo ano contam apenas de doze títulos.

Todavia é no acervo do Grêmio Literário Português do Pará que atualmente podemos encontrar o maior número de obras do escritor no que se refere à cidade de Belém. No acervo da instituição referida consta um total de 137 edições de 59 diferentes títulos de Paul de Kock. Dessas cento e trinta e sete edições, apenas uma está em língua francesa, oito são edições nacionais publicadas em língua portuguesa e cento e vinte e oito, a maioria esmagadora, são traduções portuguesas. Parcela considerável dessas edições foram enviadas de Lisboa pelo livreiro Antonio Maria Pereira (Livreiro correspondente do G.L.P.P em Portugal durante o século XIX)3. Entre 20 de outubro de 1868 e 26 de maio de 1871 foram remetidos 45 títulos de Paul de Kock, sem contar os repetidos, conforme se pode verificar nas listas de envios de livros remetidos pelo livreiro português disponíveis no G.L.P.P ${ }^{4}$. Muitos dos títulos enviados naquele período já não se encontram mais presentes no acervo da referida instituição. Dentre esses destacamos: $O$ filho de minha mulher, versão portuguesa de L'enfant de ma femme (1812), o primeiro romance escrito por Kock e publicado às suas próprias expensas: "Imprimiu-se o meu livro n'uma typographia da rua de Turenne. Quinhentos exemplares que me custaram, mettendo em conta capas e brochuras, dezeseis soldos cada volume" (KOCK, S.d, p 99). Note-se que o romancista parece ter, ao que sugere, mandado imprimir em dois suportes de qualidade material diversa: uma parte dos volumes com capas, outra parte em brochura, ou seja, a preços mais baixos. Não é de todo irrelevante observar que o trabalho de impressão, a se pautar pelo que alega o escritor, não foi levado a cabo por um livreiro-editor, mas sim por um tipógrafo e, posteriormente comercializado, à custa de uma pequena comissão, pelo livreiro Pigoreau": "havia um livreiro, chamado Pigoreau que, mediante uma ligeira comissão, se encarregaria da collocação da minha obra, no dia em

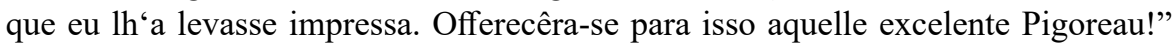
(KOCK, S.d, p.92). Outro romance de Kock remetido de Portugal que já não se encontra presente no acervo do G.L.P.P. é Meu vizinho Raymundo, tradução de Mon voisin Raymond (1823), que, segundo o autor, foi considerado por todos seu melhor romance. De $O$ coitadinho, versão portuguesa de Le cocu (1832) também já não há mais vestígios no referido acervo, a não ser seu registro na lista de envio de livros remetidos por Antonio Maria Pereira em 20 de outubro de $1868^{6}$.

Parcela considerável das edições de Paul de Kock ainda disponíveis no acervo do G.L.P.P são traduções portuguesas de Antonio Joaquim Nery e Xavier de Magalhães. O primeiro foi um dos primeiros tradutores portugueses de Paul de Kock. Durante a década de 1830 publicou inúmeras traduções de diferentes autores e outros escritos de sua autoria na tipografia de Felipe Nery denominada Typographia de Nery. Publicou ainda em outras tipografias, como a Comercial Portuense e a Patriótica. Alguns anos depois, já detentor de uma tipografia, passou a editar as próprias traduções em nome da Tipografia que denominou Neryana. Assim, além de tradutor, Joaquim Nery passou também a exercer o ofício de editor e tipógrafo. A partir de 1841, o essencial de sua produção consistiu em traduzir Paul de Kock, de quem, segundo João Luís Lisboa "publica mais de duas dezenas de títulos" (LISBOA, 2012, p. 14). As traduções das obras do romancista francês realizadas por 
Nery, sem dúvidas obtiveram um grande êxito comercial, uma vez que conforme assinala Maria de Lourdes dos Santos, quando Nery “já não tinha mais romances de Kock para traduzir, o havia de imitar na tentativa de conservar a galinha dos ovos de ouro" (SANTOS, 1985, p. 191). Dentre as edições dos títulos de Kock, traduzidos por Nery, ainda estão presentes no acervo do G.L.P.P os seguintes: Os quatro tomos de A família Gógó, de 1845, tradução de La famille Gogo [183?]; Os quatro tomos de A leiteira de Montfermeil, de 1843 e 1844, tradução de La laitière de Montfermeil (1827); Os quatro tomos de João, de 1846, tradução de Jean [181?]; Os tomos III e IV de André, o saboyano, de 1844, tradução de André le savoyard (1825); Os quatro tomos de Georgetta, ou a sobrinha do tabellião, de 1842, tradução de Georgette ou la Nièce du tabellion (1820) ; Os quatro tomos de Este senhor!, de 1842, tradução de Ce Monsieur [183?] ; Os quatro tomos de Homem da natureza e o homem civilisado, de 1843, tradução de l'Homme de la nature et l'Homme Police [182?]; Os quatro tomos de Hum jovem encantador, de 1846, tradução de Le jeune homme charmant [181?]; Os quatro tomos de Magdalena, de 1844, tradução de Magdalena [18??]; Os quatro tomos de Sem gravata, ou os moços de recados, de 1845, tradução de Sans cravate [183?].

As edições de Kock traduzidas por Xavier de Magalhães foram publicadas pela Typographia de Salles, Imprensa Minerva e Imprensa de Lucas Evangelista durante as décadas de sessenta, setenta e noventa do século XIX. Dentre as edições de Paul de Kock traduzidas por Xavier de Magalhães, presentes no acervo do G.L.P.P, encontram-se: Os pequenos regatos formam os grandes ribeiros (1867), tradução de Les petits ruisseaux (1867), O professor Ficheclaque (1867), tradução de Le professeur Ficheclaque (1873), O rapaz mysterioso da esquina (1871), tradução de Le petit bonhomne du coin (1871), Friquette (1873), tradução de Friquette (1873), Um homem atribulado (1868), tradução de Un monsieur très tourmenté [18??], Vol I e II de Os companheiros das tuberas (1870), tradução de Les compagnos de la truffe [186?], Vol. I e II de O bandido Giovanni (1866-67), tradução de Les étuvistes [18??], Vol. I e II de Um namorado caloiro (1871-72), tradução de L'amoureux transi [18??], O rapaz misterioso da esquina (1871), tradução de Le petit bonhomne du coin (1871). No que se refere o aspecto material dessas edições de Kock presentes no acervo do G.L.P.P observa-se grande parcela delas são publicações populares, brochuras produzidas a baixo custo e publicadas vários volumes?

\section{RECEPÇÃO CRÍTICA DE PAUL DE KOCK}

No que tange à recepção crítica de Paul de Kock vale notar que a popularidade do escritor durante o Oitocentos, não implicou, no entanto, em uma recepção crítica favorável de suas obras. Grande parcela dos críticos literários o considera como um autor menor, escritor das classes mais baixas, que não prezava pelo estilo e escrevia unicamente para o lucro (O’NEIL-HENRY, 2011, p. 178). Brito Broca, crítico literário e historiador brasileiro, refere-se a ele como um escritor "alegre e brejeiro" que conseguiu alcançar um vasto público no Oitocentos, tendo inclusive, andado "até pelas mãos das nossas jeunes-filles, num tempo em que elas sofriam a mais rigorosa censura doméstica nas leituras" (BROCA, 1979, p. 115-116). Como grande parte dos críticos, Broca também ressalta que na "atualidade" o romancista francês é considerado "um escritor para o povo, sem expressão literária, de há muito esquecido" (BROCA, 1979, p. 115).

Eugène de Mirecourt, em sua biografia sobre Paul de Kock sugere que o romancista francês não gozava de prestígio entre os grandes críticos literários de sua época:

[d]ans la littérature de haut parage, on a pour Paul de Kock um dédain superbe. Il faut voir le sourire de pitié qui contracte certaines lèvres lorsqu'on prononce le nom de cet écrivain. Paul de Kock, allons donc! Est-ce que Paul de Kock sait écrire? C'est le romancier des cuisinières, des valets de chambre et des portiers! ${ }^{\circ}$
7 Conferir: PAES, Alessandra Pantoja. Das imagens de si ao mundo das edições: Paul de Kock, romancista popular. 2013.205 f. Dissertação (Mestrado em Letras)- Universidade Federal do Pará, Belém, 2013. 
Ao reproduzir as supostas concepções da crítica literária sobre o romancista, enfatizando que ela não tinha sua produção em alta conta uma vez que o acusava de mal saber escrever e de fazer sucesso entre as camadas populares da sociedade - cozinheiras, porteiros, criadas de quarto - o biógrafo acaba - intencionalmente ou não - por constituir certa imagem do romancista aos olhos dos leitores: a de um escritor — "popular".

Trimm (1873), por sua vez, ao observar que entre os escritores oitocentistas não havia nenhum semelhante a Paul de Kock quando se tratava de entreter e divertir as massas, também acaba por elaborar uma imagem - "popular" do escritor francês, visto assinalar explicitamente que suas obras destinavam-se às massas: - "Parmi les écrivains de ce siècle, il en est un qui a possédé sans partage le grand talent d'amuser les masses et de les faire rire [...] Cet homme s'appelait Paul de Kock" (p.6)

Pinheiro chagas, importante crítico e escritor português durante o século XIX, acerca de Kock observa:

Paulo de Kock é uma das individualidades mais caracteristicas da litteratura francesa do século XIX. Tratado sombranceiramente pelos proceres da Crítica, é incontestável comtudo que Paulo de Kock fez rir uma geração, duas gerações aliás, porque nossos paes riram com elle, rimos nós, e estou convencido que ainda hão de rir nossos filhos e nossos netos. Um homem que exerce esta influencia não só no espírito de seus contemporaneos, mas tambem sobre o das gerações subsequentes, não é, não póde ser uma mediocridade. Elle escreve mal sem duvida, o seu estylo é rococo; em saindo do seu genero não se póde aturar [...] Quando entra no dramatico, sente-se na sua maneira um discipulo de Ducray-Duminil, e percebe-se que, se não fose a sua inexhaurivel e admiravel veia comica, Paulo de Kock escreveria Meninos das selvas, Orphãos inocentes, e outras pueridades d'este joez. Mas a veia comica lá está, e essa é admiravel e tanto mais admirável quando se liga com um talento real de observação, observação á superficie, não dizemos o contrario, mas observação em todo o caso. Paulo de Kock apanha, com uma felicidade enexcedivel, $o$ ridículo nas suas manifestações externas. $O$ ridículo dos caracteres não é sem duvida para elle, o ridículo dos Birotteau e dos Nucingem esse pertence a Balzac, mas o ridiculo exterior é completamente do domínio de Paulo de Kock. Saraus burguezes, episódios da vida de provincia, incidentes da existência quotidiana encontram em Paul de Kock um pintor sempre jovial e feliz (CHAGAS, S.d. IN: KOCK, S.d, p. V-VI).

8 " $\mathrm{Na}$ literatura de alta linhagem, tem-se um soberbo desdém por Paul de Kock. É preciso ver o sorriso de pena que contrai certos lábios quando se pronuncia o nome deste escritor. Paul de Kock, vamos lá! Será que Paul de Kock sabe escrever? Ele é o romancista das cozinheiras, dos criados e dos porteiros!"’

9 "Entre os escritores desse século, há um que possui, sem compartilhar, o grande talento de entreter as massas e fazê-los rir [...] Esse homem se chama Paul de Kock".

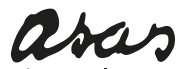
da palavra ISSN 1415-7950 
comicidade de sua narrativa, o que justificaria não considerá-lo um escritor qualquer, sem importância.

Nas últimas décadas, historiadores literários dedicados aos estudos da história do livro e da leitura no século XIX têm considerado Paul de Kock como um escritor com importante papel no mercado literário do Oitocentos, uma vez que autor de "best-sellers", que o fizeram se notabilizar entre o público leitor de sua época. A esse respeito, Anne O’Neil- Henry (2001) afirma:

we see de Kock's novels topping lists of best-sellers, we read his name mentioned among other authors able to make novel writing a lucrative business, We learn, for example, that his novels were among the first to be included in newspapers as "des supplements littéraires susceptibles d'être detachés et reliés pour former un livre" (O’NEIL-HENRY, 2011, p. 166) ${ }^{10}$

O’Neil-Henry descreve, ainda, de que forma historiadores como Martyn Lyons, James Allen Smith e Roger Chartier veem Paul de Kock

as an example or even an embodiment of a historical phenomenon: the author whose works were consumed hungrily by the new class of readers, the bourgeois author who sustained himself with his writing, the author whose work was published in different for$m s$ in conjunction with the newspaper. (O'NEIL-HENRY, 2011, p. 166). ${ }^{11}$

Para a historiadora da literatura, Judith Lyon-Caen, os romances de Paul de Kock, destinados aos leitores da pequena burguesia, podem ser lidos com um guia da sociedade francesa da época: "L'abondante production de Paul de Kock, romancier aussi populaire que méprisé, peut ainsi se lire comme um guide du monde contemporain destiné à un lectorat petit-bourgeois, parisien ou provincial" (LYON-CAEN, 2004, p. 10). Para O’Neil-Henry, tal fato ajuda a explicar a popularidade de Paul de Kock entre os leitores do século XIX (O’NEIL-HENRY, 2011, p. 158).

Sylviane Robardey-Eppstein, em estudo atual sobre a obra de Paul de Kock, observa por sua vez que há sem dúvida no romancista francês mais que um simples escritor para cozinheiras. Para a pesquisadora, por meio da leitura de alguns romances de Kock, observa-se uma "crítica literária clandestina" e uma "modernidade em movimento" na obra do referido escritor. (ROBARDEY-EPPSTEIN, 2010, p. 51. In: COMPÈRE et. al., 2010). Para a estudiosa, o esquecimento de Kock, na atualidade, não se reduz a questões estilísticas como crêem alguns críticos e estudiosos, uma vez que Alexandre Dumas também foi criticado por isso. A hipótese de Robardey-Eppstein reside no fato de os romances do escritor francês serem indiferentes à história, algo raramente presente como pano de fundo nos romances de Paul Kock.

\section{REFERÊNCIAS}

ABREU et alli. Caminhos do romance no Brasil: séculos XVIII e XIX. Disponível em: <www.caminhosdoromance.iel.unicamp.br/estudos/.../caminhos.pdf>. Acesso em 12 de janeiro de 2013

AUGUSTI, Valéria. O livreiro e o gabinete: considerações sobre uma parceria comercial. In: II LIEHD (Seminário Brasileiro Livro e História Editorial. Disponível em: <www.livroehistoriaeditorial.pro.br/ii pdf/Valeria_Augusti.pdf $>$. Acesso em 21 de setembro de 2016

BROCA, Brito. Românticos, pré-românticos e ultra-românticos: vida literária e romantismo brasileiro. São Paulo: Editora Polis, 1979.
10 "Vemos os romances de Kock cobrindo listas de best-sellers, lemos seu nome mencionado entre outros autores capazes de fazer da escrita de romances um negócio lucrativo, aprendemos, por exemplo, que seus romances foram os primeiros a serem incluídos nos jornais como: 'suplementos literários suscetíveis de serem destacados e ligados para formar um livro"".

11 "Como um exemplo ou mesmo encarnação de um fenômeno histórico: o autor cujas obras foram consumidas avidamente pela nova classe de leitores, o autor burguês que viveu de sua pena, o autor cujo trabalho foi publicado em diferentes formas em conjunto com o jornal".

COMPÈRE, Daniel et al. Le rocambole: bulletin des amis du roman populaire. Paris: Printemps, 2010. 
KOCK, Paulo de. Memorias de Paulo de Kock. Tradução de Pinheiro Chagas. Lisboa: C.S. AFRA e Cia. S. d.

LISBOA, João Luís. Do editar ao editor: Portugal e as transformações no mundo do impresso no século XIX, p. 14. In: Escola São Paulo de estudos avançados sobre a globalização da cultura no século XIX. Disponível em: $<$ www.espea.iel.unicamp. br>. Acesso em 12 de setembro de 2013.

LYON-CAEN, Judith. Saisir, décrire, déchiffrer: les mises en texte du social sous la monarchie de Juillet. Revue historique, 2004/2 n 630, p. 303-331. DOI: 10.3917/ rhis.042.0303. Disponível em: < http://www.cairn.info/revue-historique-2004-2-page-303.htm>. Acesso em 13 de abril de 2016.

MARTINS, Ana Luiza. Gabinetes de leitura na Província de São Paulo: a pluralidade de um espaço esquecido (1847- 1890). Dissertação de mestrado. São Paulo: Faculdade de Filosofia, Letras e Ciências humanas, Universidade de São Paulo, 1990.

MIRECOURT, Eugène. Les contemporains: Paul de Kock. 6. ed. Paris: Gustave Havard, Éditeur, 1856. Versão eletrônica. Disponível em: <http://archive.org/details/ pauldekock00mireuoft>. Acesso em 23 de setembro de 2016

MÜLLER, Andréa Correa Paraíso. A ficção francesa e a consolidação do romance no Brasil. Disponível em: <ebooks.pucrs.br/edipucrs/Ebooks/Web/978-85-3970198.../7.pdf>. Acesso em 25 de agosto de 2015.

NADAF, Yasmin Jamil. O romance - folhetim no Brasil: um percurso histórico. Letras. Santa Maria, v.19, n. 2, p. 119- 138, jul./dez. 2009. Disponível em: <coralx2. ufsm.br/revistaletras/artigos_r39/artigo39_008.pdf>. Acesso em 22 de Janeiro de 2016.

O'NEIL-HENRY, Anne T. Parisian Social Studies: Positivism and the Novels of Balzac, Paul de Kock, and Zola. Dissertation submitted in partial fulfillment of the requirements for the degree of Doctor of Philosophy in the Department of Romance Studies in the Graduate School of Duke University. 2011. Versão eletrônica. Disponível em:<http://dukespace.lib.duke.edu/dspace/bitstream/handle/10161/3931/ ONeilHenry_duke_0066D_10873.pdf?sequence=1>. Acesso em 12 de março de 2015

QUEIRÓZ, Juliana Maia. Em busca de romances: um passeio por um catálogo da Livraria Garnier. In: ABREU, Márcia (Org). Trajetórias do romance: circulação, leitura e escrita nos séculos XVIII e XIX. Campinas, SP: Mercado de Letras, 2008.

SALES, Germana Maria Araújo. Circulação de romances no século XIX. S. d. p. 1-12. Disponível em: HTTP://www.alb.com.br/anais17/txtcompletos/sem17/COLE 1360. pdf SEABRA, Bruno. Paulo. Versão eletrônica. Disponível em: $<$ http://www.dominiopublico.gov.br/download/texto/bi000133.pdf>. Acesso em 20 de setembro de 2016.

SANTOS, Maria de Lourdes Lima dos. As penas de viver da pena (aspectos do mercado nacional do livro no século XIX). Análise social, vol. XXI, 1985, pp. 187-227. Disponível em: <analisesocial.ics.ul.pt/.../1223477558I9uAH0jy3Un61TI1.pdf>. Acessso em 23 de agosto de 2015.

SCHAPOCHNIK, Nelson. Os jardins das delícias: gabinetes literários, bibliotecas e figurações da leitura na corte Imperial. Tese de doutorado. São Paulo: Departamento de História da FFLCH, Universidade de São Paulo, 1999.

TRIMM, Timothée. La vie de Charles Paul de Kock. Paris: Collection George Barba, 1873. Versão eletrônica, disponível em: $<$ http://www.archive.org/details/laviedechpauldek00lesp $>$. Acesso em 10 de maio de 2016. 